\title{
Jueves 8 de marzo de 2018, 7 a.m.
}

\author{
ANALÍA GERBAUDO Universidad Nacional del Litoral - CONICET, Argentina /
}

analia.gerbaudo@conicet.gov.ar/agerbaudo@fhuc.unl.edu.ar

\author{
Is it necessary to respond to every interpellation, to everyone no matter who, to every question, and \\ especially to every public attack? \\ Jacques Derrida, Biodegradables. Seven Diary Fragments
}

\begin{abstract}
A pesar de la fecha, esta nota no alude a las luchas de las mujeres por sus derechos, aunque el episodio en cuestión tal vez también podría leerse desde esa clave. Si tuviera el don de la palabra literaria me atrevería, tal como lo hizo Jacques Derrida en Francia o Alberto Giordano en Argentina, a ensayar esas producciones sacrílegas que explotan los protocolos del diario «íntimo» para decir, tanto en libros como en ensayos publicados en prestigiosas revistas, lo que desde otro género sería imposible.

Derrida experimenta con estas formas en «Envois», un texto de 1980. Pero su composición más revulsiva y, no casualmente, poco retomada, la produce en 1989 y la publica en Critical Inquiry: en «Biodegradables. Seven Diary Fragments», simula recoger fragmentos esbozados durante siete días de escritura. El «juego» (palabra sobre la que trabaja buscando que sus performances contribuyan a restituirle su poder y su potencia -1972:72—) le lleva más de 60 páginas. Como en todo diario «íntimo» (es el juego el que habilita la mimesis de sus protocolos), el ritmo es discontinuo: Derrida nos presenta las notas que escribe entre el 24 de diciembre de 1988 y el sábado 4 de febrero de 1989 . Se trata de siete entradas datadas en siete días con obsesivos registros de la hora de producción. Los puntos que aborda son varios (la resistencia a la lectura, la supervivencia de los textos, los modos de intervenir en la escena pública, la tensión entre «buena conciencia» y «responsabilidad» con su correlato en la tensión entre «moral» $\mathrm{y}$ «ética») y se desprenden de un asunto que, por primera vez, puede abordar con la agudeza incisiva que caracteriza su escritura: el «affaire De Man».' La simulación de la escritura de este diario es el recurso que emplea para responder a las críticas recibidas por su primera lectura del asunto (Derrida 1988). Lo que interesa traer a la conversación, en esta oportunidad, son sus preguntas éticas. Esas que, sin duda, afina a partir de este suceso que lo conmueve profundamente, en más de un sentido: no se trata sólo del cuidado de la memoria del amigo muerto, no se trata sólo de una discusión que lo involucra como parte de la comunidad judía a la que pertenece, no se trata sólo de una batalla académica contra la desconstrucción. Se trata de cada una de estas cosas, y más.
\end{abstract}

Para citar este artículo: Gerbaudo, Analía (2018). «Jueves 8 de marzo de 2018, 7 a.m.». El taco en la brea 7 (diciembre-mayo), 2-6 Santa Fe, Argentina: UNL. DOI: https://doi.org/10.14409/tb.voi7.7349 
Se trata también de un hecho que lo lleva a solicitar las reglas del «campo» (Derrida 1989:836) académico. Es notable: a pesar de sus diferencias teóricas, y en buena medida, por muchas de sus coincidencias éticas y políticas, ${ }^{2}$ Derrida cita aquí la terminología acuñada por Pierre Bourdieu para aludir a ciertas «batallitas» libradas en ese «campo autónomo» (836) configurado por los estudios literarios. Es a partir de esas «batallitas» que despliega estos primeros esbozos de su «ética de la discusión» (Derrida 1990) intelectual: la pobreza argumentativa de los ataques a De Man y a la desconstrucción en general vía su texto (Derrida 1988) lo llevan a omitir los nombres de sus oponentes para, directamente, entrar a los puntos que le interesan. Podría decirse que su pregunta central, anticipada desde el título, gira alrededor de lo que sobrevive o resta o supera el paso del tiempo: considerando la amnesia general a partir de la cual se construye la cultura, Derrida se pregunta qué textos no están sujetos a la biodegradabilidad y, a partir de esta pregunta, desprende las directamente ligadas a una ética de la discusión. Entre otras: cuáles son las críticas o ataques que merecen una respuesta; cómo responder de algún modo contribuye a darle entidad a problemas que no lo merecen; cuándo y en qué sentido no responder es la mejor respuesta, la más generosa.

Como Derrida, que decide escribir sobre su amigo Paul De Man con la fantasía de lograr, al menos, algo de justicia crítica en un medio transido por «perversiones» (Derrida 1989:837), quisiera escribir sobre Julia Bernardi que fue, hasta el año pasado, administradora y bibliotecaria de la casa que el Ministerio de Educación de Argentina tiene en París.

Julia fue separada de su cargo por «faltas graves». Quienes la conocimos por su trabajo, ya sea en la biblioteca de la maison o luego en la sección administrativa, quienes tuvimos la oportunidad de habitar esa casa nuestra, sabemos del compromiso, la responsabilidad y el amor puestos en el ejercicio de sus tareas. Muchos de esos que la conocimos, firmamos una solicitada pidiéndole al Ministerio marcha atrás. Muchos de esos también dimos luego nuestro testimonio en defensa de Julia ante la justicia francesa.

No sabemos qué va a pasar con Julia. Nos gustaría imaginar que Julia, a la que no le hemos encontrado quienes la conocimos ni una falta, y menos grave (salvo que sea una «falta» $\mathrm{y}$ «grave» tener una posición política tomada — porque si hay algo que Julia tenía, era una posición política tomada-), podrá volver a su cargo. Nos gustaría imaginar que no hay en este país otras Julias separadas de sus cargos por la "falta» (y "grave») de tener una posición política (y/o partidaria) tomada. Nos gustaría escribir esto sin miedo (porque tenemos, se sabe, una posición política tomada). Y como cuando la conocimos a Julia, nos gustaría imaginar nuestra internacionalización como la transferencia hacia el extranjero de lo que producíamos los científicos desde Argentina (nos gustaría no volver a sentir la internacionalización como un espacio posible de supervivencia, un camino a transitar por si acaso, por si las cosas se complican....).

La internacionalización de nuestras investigaciones es un objetivo perseguido por esta revista (se trata, todavía, de un trabajo animado por el deseo y no por el temor). En ese sentido, es motivo de alegría la incorporación a nuestro comité científico de dos profesores que llevan nuestros textos a otros marcos institucionales: gracias a Stefano-Maria Evangelista y Laura Pennacchietti por hacer circular en otros territorios, nuestra palabra. 


\section{Notas}

1 En 1988 Derrida publica «Like the sound of the sea deep within a shell: Paul De Man's War»: se trata del único texto con fisuras argumentativas que he localizado en su producción (debo confesarlo, ya no tengo la fantasía de leer «todo Derrida», tarea literalmente im-posible, tal como se desprende de la biografía que Benoît Peeters ha escrito documentando el volumen apabullante de su obra; no obstante, lo que leído es bastante...). Derrida responde entonces a un pedido de Critical Inquiry: en 1988, cuatro años después de la muerte de Paul De Man, salen a la luz un conjunto de artículos escritos por éste bajo la ocupación alemana de Bélgica entre 1941 y 1942 para los periódicos Le Soir y Het Vlaamsche Land. Ortwin De Graef, un investigador belga que estaba preparando una tesis doctoral sobre De Man, los descubre. Son alrededor de ciento cincuenta escritos; en su mayor parte, reseñas de libros que presentan una ambigua posición respecto del nazismo. A pedido de Critical Inquiry, Derrida se expide sobre el asunto. Conmovido, desconcertado, escribe un texto desequilibrado que no sólo defiende lo éticamente indefendible sino que además apela a recursos que sistemática y regularmente cuestiona: recurrir a datos biográficos o a testimonios de testigos para refutar conjeturas o tesis desprendidas de movimientos retóricos de la escritura (Derrida 1988). Se trata de un texto desacertado que contradice uno a uno los supuestos epistemológicos y teóricos de la desconstrucción: en su vano intento de detener la proliferación de significados que los textos de De Man provocan, repite los equívocos que había denunciado con mayor regularidad y virulencia tales como utilizar los procedimientos de la desconstrucción allí mismo donde debiera tomarse una posición a favor o en contra dado el calibre del problema tratado; apelar a la intencionalidad del autor más que a los efectos de sentido que se derivan de su escritura, además de la ya mencionada apelación bio-gráfica y testimonial.

2 En otros lugares he discutido la reducción del término «político» al plano declarativo y, más aún, partidario. Y lo he hecho a partir de un análisis de las políticas de la desconstrucción derrideana (cf. Gerbaudo 2007, 2014). Al respecto, hay un evento internacional ilustrativo: el 6 y 7 de diciembre de 2008 se celebra en París el Colloque International Derrida politique. Este coloquio (organizado por el Institut des Hautes Etudes en psychanalyse, el Laboratoire Disciplinaire «Pensées des sciences» [École Normale Supérieure], los archivos Husserl [ENS-CNRS] y el Comité editorial de la obra de Derrida con motivo de la aparición de Derrida pour les temps àvenir y La bête et le souverain publicados respectivamente por las editoriales Stock y Galilée, también patrocinantes del evento) se difundía previamente con la siguiente introducción, incluida luego en el programa de mano: «Si la pensée derridienne ne développe pas une "philosophie politique" au sens traditionnel, c'est-à-dire toujours marquée par l'histoire de la métaphysique, elle ne constitue pas moins un mode de pensée fondamentalement politique. Mais autrement. Cette pensée demeure incomprise pour "ceux qui ne reconnaissent le politique qu'à l'aide des panneaux de signalisation d'avant la guerre". Toutes les interventions de Derrida dans des situations politiques concrètes s'inscrivent dans le prolongement d'un acte de déconstruction qui se situe en amont des habituelles prises de position qu'appellent les préjugés de la conscience bavarde. Leurs gesticulations tournent court devant la "chose même" du politique en ne cessant de répéter, sans même la conscience ou la mémoire du ressassement. S'il n'y a pas de démocratie sans mise en commun, il n'y a pas non plus de démocratie sans respect de la singularité et de l'altérité irréductible qui échappent à toute communauté. Dans l'urgence de penser ce qui vient de nouveau, de penser de manière neuve ce qui est nouveau et ce qui revient — en parlant de la politique sans parler politique-, Derrida nous invite à révolutionner le concept même de révolution». El programa anunciaba la lectura de «prises de position politique par Jacques Derrida rappelées par Chantal Talagrand et Daniel Mesguich» entre las exposiciones que, más allá de la apertura a cargo de Marc Crépon y René Major, pueden dividirse en dos grupos: las que se centran en cuestiones políticas ligadas especialmente al orden declarativo (cf. Bennington, Anidjar, Regazzoni, Kamuf, Major, Alunni, Lisse, Ukai, Mallet) y las que focalizan en performances con derivas políticas mayormente asociadas a su trabajo sobre la literatura y/o la escritura (cf. Michaud, Goldschmit, Dutoit, Cixous, Dufourmantelle, Habib, De Peretti y Rocha, Ronell, Nancy). Vale la pena resaltar que esta taxonomía es congruente con el resto de la producción de los conferencistas sobre la cuestión. Por ejemplo, la exposición de Cristina De Peretti y Delmiro Rocha, "Des ses premières textes», se articula recursivamente con los «primeros textos» que De Peretti escribía sobre Derrida, la desconstrucción y su trabajo político. En su muy temprano artículo «Las barricadas de la descontrucción» señalaba: «La desconstrucción (...) no opera nunca exclusivamente sobre 
enunciados, sobre contenidos de sentido, sobre la "edificación" formal y semántica de los filosofemas. Se ejerce asimismo sobre las relaciones y estructuras institucionales (políticas, económicas, sociales), sobre las formas históricas de su configuración» (42). Es oportuno subrayar la elocuente condensación lograda en el título del ensayo de De Peretti y Rocha: un énfasis que marcha a contrapelo de otro, promovido de algún modo por el coloquio. En ese sentido, la pronunciada atención a sus «prises de position politique» y a textos como Spectres de Marx (1993) y La bête et le souverain (2008) no contribuyen a despejar los malentendidos en torno a la desconstrucción leída desde el «hilo» (cf. Derrida 1972) escogido para aquella ocasión. Más aún: abonan la reducción de su trabajo político a sus aspectos explícitos y declarativos que además, según una más o menos extendida vulgata, comenzarían con Spectres de Marx para pronunciarse después. Al respecto cabría realizar una distinción, en la misma línea que la que plantean Nancy y De Peretti y Rocha: ya en 1982, en una entrevista realizada por Christian Descamps, Derrida diferencia el posicionamiento radical exigido por situaciones que no admiten «desconstrucción» («Las críticas frontales y simples son necesarias siempre, son la ley de rigor en la urgencia moral o política, incluso si cabe discutir sobre la mejor formulación para este rigor. Tiene que ser frontal y simple la oposición a lo que pasa actualmente en Polonia o en Oriente Medio, en Afganistán, en El Salvador, en Chile o en Turquía, a las manifestaciones de racismo más próximas a nosotros, y a tantas cosas más singulares y sin denominación de Estado o Nación» —Derrida, 1982:27—) del "pensamiento político» que se libra, "casi inaudible», a través de un trabajo sobre los "códigos» (29), sobre los protocolos institucionales. No olvidemos que ya en su poco convencional «defensa de tesis» despuntaba esta cuestión: «la forcé reproductive de l'autorité s'accommode plus facilement de déclarations ou de thèses soi-disant révolutionnaires dans leur contenu codé pourvu que soient respectés les rites de légitimation, la rhétorique et la symbolique institutionnelle qui désamorcent et neutralisent tout ce qui vient d'ailleurs. L'irrecevable, c'est ce qui, par-dessous les positions ou les thèses, vient de ranger ce contrat profond, l'ordre de ces normes, et qui le fait déjà dans la forme du travail, de l'enseignement ou de l'écriture» (1980b:451-451). Esta afirmación, lejos de reducirse al plano declarativo, se actúa en performances entre las que se destacan, entre muchas otras, el corpus que prepara para esa misma escena «doctoral» (cf. Derrida 198ob).

\section{Bibliografía}

Alunni, Charles (2008). «D’un autre cap». Colloque International Derrida politique. París: ENS.

Anidjar, Gil (2008). «Politiques de la laïcité». Colloque International Derrida politique. París: ENS.

Bennington, Geoffrey (2008). «Politique, Derrida!». Colloque International Derrida politique. París: ENS.

Bourdieu, Pierre (1985). «Effet de champ et effet de corps». Actes de la Recherche en Sciences Sociales 59, 2-73.

Cixous, Hélène (2008). Table ronde «Déconstruction/Psychanalyse du politique». Colloque International Derrida politique. París: ENS.

De Peretti, Cristina (1989). «Las barricadas de la desconstrucción». Anthropos. Revista de Documentación Científica de la Cultura 93, 40-43.

De Peretti, Cristina y Delmiro Rocha (2008). «Dès ses premières textes». Colloque International Derrida politique. París: ENS.

Derrida, Jacques (1972). La dissémination. París: Du Seuil.

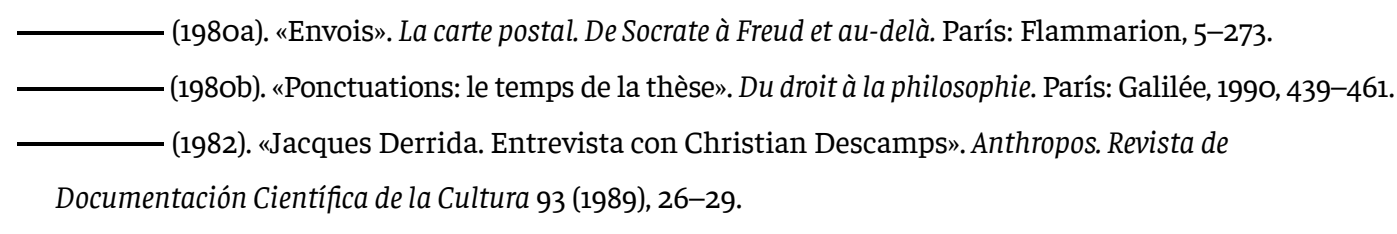
(1988). «Like the sound of the sea deep within a shell: Paul De Man's War». Memoires for Paul De Man. Revised edition. New York: Columbia University Press, 1989, 155-263. (1989). «Biodegradables: Seven Diary Fragments». Critical Inquiry 15(4), 812-873. Traducción del francés por Peggy Kamuf. 
— (1990). «Postface: Vers une éthique de la discussion». Limited Inc., a b c... París: Galilée, 199-285.

(1993). Spectres de Marx L'État de la dette, le travail du deuil et la nouvelle Internationale. París:

Galilée.

(2008). Séminaire La bête et le souverain. Volume 1(2001-2002). París: Galilée.

Dufourmantelle, Anne (2008). Table ronde «Déconstruction/Psychanalyse du politique». Colloque International Derrida politique. París: ENS.

Dutoit, Thomas (2008). “"Je suis une cigale": 1"Animot" poético-politique». Colloque International Derrida politique. París: ENS.

Gerbaudo, Analía (2007). Derrida y la construcción de un nuevo canon crítico para las obras literarias. Córdoba: Universitas, Sarmiento/Universidad Nacional de Córdoba.

(2014). «Algo más sobre protocolos de escritura, literatura y política en Jacques Derrida».

Coloquio Homenaje a Jacques Derrida «La soberanía en cuestión». Buenos Aires: Museo del Libro y de la Lengua.

Goldschmit, Marc (2008). «La politique depuis la fin du monde». Colloque International Derrida politique. París: ENS.

Habib, Stéphane (2008). Table ronde «Déconstruction/Psychanalyse du politique». Colloque International Derrida politique. París: ENS.

Kamuf, Peggy (2008). «Le philosophe, en tant que tel, et la peine de mort». Colloque International Derrida politique. París: ENS.

Lisse, Michel (2008). «Une politique pour la vie». Colloque International Derrida politique. París: ENS.

Major, René (2008). Table ronde «Déconstruction/Psychanalyse du politique». Colloque International Derrida politique. París: ENS.

Mallet, Marie-Louise (2008). «Le horla ou la folie de l'ipséité souveraine». Colloque International Derrida politique. París: ENS.

Michaud, Ginette (2008). «Seuils et tremblements». Colloque International Derrida politique. París: ENS.

Nancy, Jean-Luc (2008). «Le secret, le sens». Colloque International Derrida politique. París: ENS.

Peeters, Benoît (2010). Derrida. París: Flammarion.

Regazzoni, Simone (2008). «Au-delà de la pulsion de pouvoir. Derrida et la déconstruction de la souveraineté». Colloque International Derrida politique. París: ENS.

Ronell, Avital (2008). «Derridémocratie». Colloque International Derrida politique. París: ENS.

Ukai, Satoshi (2008). «De "monstrueux comme si". Pour une historie du mensonge en politique au Japon».

Colloque International Derrida politique. París: ENS. 